\title{
Oral Manifestations of Paediatric HIV Infection
}

\author{
Omolola Orenuga ${ }^{1}$, Mutiat Obileye ${ }^{2}$, \\ Christiana Sowole ${ }^{3}$ and Gbemisola Agbelusi ${ }^{1}$ \\ ${ }^{1}$ Faculty of Dentistry, College of Medicine, University of Lagos, Lagos \\ ${ }^{2}$ Dental Clinics, Lagos State University Teaching Hospital, Ikeja \\ ${ }^{3}$ Dental Public Health, Chatham \\ 1,2Nigeria \\ ${ }_{3}^{3}$ United Kingdom
}

\section{Introduction}

Immune defects in children have been shown to have profound effects on oral tissues. (Joint United Nations Program on HIV/AIDS [UNAIDS], 2002, 2005).

Oral lesions are among the earliest and most common clinical sign of infection with the Human Immunodeficiency Virus (HIV), are important indicators and can predict progression of HIV infection. A number of studies have shown that oral lesions are common in HIV infected patients. Knowledge and awareness of the signs and symptoms, of oral lesions that may be indicative of the patients' HIV status will assist in instituting the appropriate careful steps of management at an early stage for better prognosis. (Chadwick \& Yogev, 1995; Eldridge \& Gallagher, 2000; Fowler et al., 2000; Gray \& McIntyre, 1999; RamosGomez, 1997; Sullivan, 2003; Working Group on Mother To Child Transmission of HIV, 1995). A thorough understanding of these lesions has implications for all health care professionals.

HIV progression is faster and more severe in children, due to the immaturity of the immune system. Most children born with HIV infection are symptomatic at birth, however time between birth and initial symptoms and signs varies considerably. The median age of paediatric patients at the time of an AIDS diagnosis is 12 months with oral manifestations often the first sign of infection in approximately half of all infected children. (Magalhaes et al, 2001; Ramos-Gomez, 1997, Ramos-Gomez et al., 2000; Rosemberg \& Faucias 1994).

Most children will develop one or more oral manifestation of HIV infection during the course of the disease, similar to that seen in adults. (Leao et al., 2009; UNAIDS 2002, 2004). AIDS has emerged as the seventh leading cause of death among infants and children in the United States of America (USA), and a leading cause of death among minority groups and in low income countries (LINCs). (Centres for Disease Control and Prevention [CDC] 1993; Ramos-Gomez et al., 2000; UNAIDS, 2009)

Majority of paediatric HIV infections are the result of Mother To Child Transmission (MTCT). The increasing proportion of infected children achieving adulthood highlights the need for multidisciplinary approach to management and thus facilitates transition to adult care while maintaining strategies specific for mother to child acquired infections. (Giaquinto et al, 2010; Massarente et al 2011; Swendeman et al, 2009). 
Evidence of HIV disease progression in both adult and paediatric patients is marked by oral manifestations and general periodontal status, and oral symptoms and signs may have prognostic value that is independent of CD4 status or other commonly used markers. (Greenspan \& Greenspan, 1999; Ramos-Gomez et al., 2000). Oral lesions commonly associated with paediatric HIV infection include oral candidiasis, herpes simplex virus infection, linear gingival erythema and recurrent aphthous ulcers. Oral candidiasis is the commonest oral manifestation in children and may be associated with burning sensation in the mouth, problems with nutrition and changes in taste. (Orne-Glieman et al., 2008) Oral candidiasis has also been associated with HIV disease progression and immune system deterioration as evidenced by low CD4 counts in both adults and children with the infection. However, parotid gland enlargement is indicative of a better prognosis, with slower disease progression or long term survival. (Katz et al., 1993; Magalhaes et al., 2001; Ramos-Gomez et al., 1999)

Recognition of these early oral signs during routine examinations and in surgical procedures is important for diagnosis and treatment, which allows for early intervention, clinical staging of the infection leading to better prognosis, reduced morbidity and improved quality of life in this population. The early diagnosis of these lesions will help in assessing disease progression especially in LINCs where limited resources hamper disease specific interventions.

\section{Literature review}

\subsection{Epidemiology}

HIV is a global pandemic, which continues to escalate throughout developing countries compared to a notable stabilization in new cases and fatalities in some developed countries. The number of people living with HIV worldwide continued to grow in 2008, reaching an estimated 33. 4 million. The total number of people living with the virus in 2008 was more than $20 \%$ higher than the number in 2000, and the prevalence reported to be roughly threefold higher than in 1990. (UNAIDS, 2009). The continuing rise in the population of people living with HIV reflects the combined effects of continued high rates of new HIV infections and the beneficial impact of antiretroviral therapy. As of December 2008, approximately 4 million people in low- and middle-income countries were receiving antiretroviral therapy. An estimated 430,000 new HIV infections occurred among children under the age of 15 in 2008. Most of these new infections are believed to stem from transmission in-utero, during delivery or post-partum as a result of breastfeeding. The number of children newly infected with HIV in 2008 was roughly 18\% lower than in 2001. To date, UNAIDS estimates that 40 million are living with HIV/AIDS, with more than 95\% in developing countries, including 28. 5\% in sub-Saharan Africa, and out which at least 2. 1 million are children under the age of 15years. (Barnett \& Whiteside, 2006; Greene, 2007; Nigeria, 1992; UNAIDS, 2002, 2004, 2005, 2006, 2009).

Studies on oral manifestations of HIV infection have reported that these lesions are common, with a wide variation in the prevalence of lesions; $41 \%$ to $99.5 \%$ prevalence reported in studies carried out on populations of intravenous drug abusers and other risk groups. (Arendorf et al., 1998; Barone et al., 1990; Ceballos-Salobrena et al., 1996; Onunu \& Obuekwe, 2002; Sauer et al.,1995; Schimdt-Westhausen et al 1997., Ukpebor \& Braimoh, 2006; Wright, 2003). The wide variations in the prevalence of oral lesions in the literature have been attributed to a number of factors, and include sample randomization, sample size, 
clinical stage at presentation, risk group, education, race, socioeconomic status and access to health care. Most studies have reported a high prevalence of at least one oral lesion in children with HIV infection, with oral candidiasis being the most prevalent oral condition. (Barasch et al., 2000; Glick, 2005; Katz et al., 1993; Lamster et al., 1994; Ramos-Gomez et al., 1996; Yengopal et al., 2011).

\subsection{Pathogenesis}

The acquired immunodeficiency syndrome (AIDS) was first observed in 1981 in young male homosexuals in the United States of America (USA); though there are evidences that sporadic cases may have been in existence before then. (Olumide, 2002; Scully, 1997) The causative organism was identified and named as the Human Immunodeficiency Virus (HIV). It is a member of the lentevirus subfamily. Two strains HIV-1 and HIV-2 the primary aetiological viruses for AIDS were described in 1983 and 1986 respectively. However, HIV infection in children was first described in 1983. (Oleske et al., 1983). HIV disease in infants and children, as in adults, is a progressive disease with a clinical spectrum ranging from asymptomatic infection to profound and eventual fatal immunosuppression. AIDS is the point on this spectrum where significant immunodeficiency causes emergence of conditions that meet the criteria for the Centres for Disease Control (CDC) definition of AIDS diagnosis. (Ammann, 1999). The hallmark of immunodeficiency caused by HIV infection is the depletion of cells of the immune system: CD4+ T lymphocytes, macrophages, monocytes and dendritic cells that express the CD4 receptors. The gradual decrease in the number of cells of the immune system and the functional decline of these cells lead to the breakdown of the immune system, exposing infected individuals to a wide variety of viral, bacterial, fungal and parasitic infections as well as the development of malignancies that result in full blown AIDS. These conditions when occurring in the mouth constitute the oral manifestations of HIV/AIDS and may be indicators of HIV infection. (Agbelusi \& Wright 2005; Zijenah \& Katzenstein, 2002).

\subsubsection{Transmission}

The epidemic in children has risen globally due to the worldwide increase in HIV prevalence in women of childbearing age. Majority of paediatric HIV/AIDS cases are as a result of transmission from mother to child. Though the source and route of transmission is multifactorial, mother to child transmission (MTCT) is the commonest mode of transmission of HIV in children. In the absence of any intervention, the risk of MTCT is $15-30 \%$ in nonbreastfeeding populations and $20-45 \%$ among populations who practice prolonged breastfeeding. It is estimated that $50 \%$ of HIV-infected infants will die before the age of two. (De Cock et al., 2000; Newell et al., 2004).

Effective prevention of mother-to-child transmission involves simultaneous support for several strategies that work synergistically to reduce the odds that an infant will become infected as a result of exposure to the mother's virus. Through the reduction in overall HIV among reproductive-age women and men, the reduction of unwanted pregnancies among HIV-positive women, the provision of antiretroviral drugs to reduce the chance of infection during pregnancy and delivery and appropriate treatment, care and support to mothers living with HIV (including infant feeding), programmes are able to reduce the chance that infants will become infected. In ideal conditions, the provision of antiretroviral prophylaxis and replacement feeding can reduce transmission from an estimated $30 \%$ to $35 \%$ with no 
intervention to around $1 \%$ to $2 \%$. Most countries have not yet reached all pregnant women with these services, let alone significantly reduced HIV prevalence among reproductive-age individuals or unwanted pregnancies among HIV-positive women. (Ammann 2006; UNAIDS 2009).

\subsection{Clinical aspect of HIV disease in children}

\subsubsection{Orofacial manifestations}

The development of HIV infection in children has different characteristics to those noted in adults, due mainly to the earlier acquisition of the virus, combined with the immaturity of the immunologic system and other body structures. The clinical features of pediatric HIV infection includes the appearance of various oral lesions, some of which are considered AIDS diagnosis markers, such as recurrent oral candidiasis and chronic enlargement of the parotid. The most frequently associated oral lesions are: candidiasis, herpes simplex infection, linear gingival erythema (LGE), parotid enlargement and recurrent aphthous stomatitis. Other viral and bacterial infections, including periodontal infections are less commonly associated, while hairy leukoplakia and Kaposi's sarcoma are rarely seen in HIVinfected children. (Greenspan D, 1998; Soares et al., 2004). The oral manifestations of HIV disease in adults and children were classified before the advent of anti-retroviral drugs (ART). Patients who do not receive ART are likely still to have the common oral features of HIV disease: candidiasis (typically pseudomembranous candidiasis), hairy leukoplakia, Kaposi's sarcoma, non-Hodgkin's lymphoma and, perhaps periodontal disease. (Frezzini et al., 2006). Dry mouth as a result of decreased salivary flow rate may not only increase the risk of dental caries but further impact negatively on quality of life because of difficulty in chewing, swallowing and tasting food. According to the World Oral Health Report 2003 priority is given to effective prevention of oral manifestations of HIV/AIDS through additional actions. These actions are integral components of $\mathrm{WHO}$ and joint United Nations global programs for control of HIV/AIDS. These collaborative programs include but are not limited to the identification of the most indicative oral manifestations of HIV/AIDS, training of other health professional and dissemination of information on disease prevention and recognition. (Petersen, 2003; 2004; UNAIDS 2004; WHO, 2003).

\subsubsection{Overview of treatment}

Anti retroviral drugs (ARDs) used in the management of HIV-infection now principally comprise four classes of retroviral agents:

Nucleoside analog reverse transcriptase inhibitors (NRTIs);

Non-nucleoside analog reverse transcriptase inhibitors (NNRTIs);

Protease inhibitors (Pis) and Entry inhibitors.

However, effective anti-retroviral therapies are rarely available to HIV-infected people in LINCs and the developing world, particularly areas of Africa. Moreover, only a handful of ARDs in the current WHO guidelines have solid formulations in doses appropriate for pediatric use and pediatric fixed-dose drug combinations are scarce.

\section{Oral manifestations in paediatric HIV infection}

\subsection{Classification of oral lesions in HIV infection}

Oral lesions seen in HIV disease have been classified by the EC Clearing house on oral problems related to HIV infection and WHO collaborating centre on Oral manifestations of 
the immunodeficiency virus into three main groups. (Coogan et al 2005; Greenspan JS \& D, 1995; Leao et al., 2009). These are:

Group 1: Lesions strongly associated with HIV infection

Group 2: Lesions less commonly associated with HIV infection

Group 3: Lesions seen in HIV infection

These lesions have also been grouped according to their aetiology as:

- Neoplastic conditions

- Bacterial infections

- Fungal infections

- Viral infections

- Autoimmune disorders

- Neurological disturbances

- Other conditions.

The spectrum of oral diseases in HIV infected children differs significantly from that of adults. These differences have been attributed to differences in the viral induced immunopathologic changes in these two different age groups as well as to being the result of decreased exposure at a young age to certain viruses, which reduces the risk for diseases such as oral hairy leukoplakia, oral warts, Kaposi's sarcoma and lymphoma. Despite this limited range of diseases, most children will develop one or more oral manifestation of HIV infection during the course of the disease, similar to that seen in adults Orofacial manifestations of paediatric HIV infection have been divided into four groups. (Flaitz \&Hicks, 2003; Fonseca et al., 2000).

\subsubsection{Oral lesions commonly associated with paediatric HIV infection}

- Candidiasis-

Pseudomembranous

Erythematous

Angular cheilitis

- Herpes simplex viral infection

- Linear gingival erythema

- Major salivary gland enlargement

- Recurrent aphthous ulcers-

Minor, major, and herpetiform

\subsubsection{Oral lesions less commonly associated with paediatric HIV infection}

- Bacterial infections

- Periodontal diseases

- Necrotizing ulcerative gingivitis (NUG)

- Necrotizing ulcerative periodontitis (NUP)

- Necrotizing stomatitis (NS)

- Viral infections (cytomegalovirus, human papilloma virus, varicella zoster virus, molluscum contagiosum)

- Xerostomia

3.1.3 Oral lesions strongly associated with HIV infection but rare in children

- Kaposi's sarcoma 
- Non-Hodgkin's lymphoma

- Oral hairy leukoplakia

- Tuberculosis-related ulcers

\subsubsection{Oral conditions with increased severity in paediatric HIV infection}

- Gingivitis and periodontitis (increased gingival and plaque indices)

- Over-retained primary teeth

- Delayed eruption of primary and permanent teeth

- Primary dentition caries

\section{Oral lesions commonly associated with paediatric HIV infection}

\subsection{Oral candidiasis}

This is the most common oral soft tissue manifestation of paediatric HIV infection. (Barasch et al., 2000; Fonseca et al 2000; Kline 1996; Ramos-Gomez et al., 1999). Candidiasis is often the first clinically observable manifestation of HIV infection, with up to $72 \%$ of these children developing the disease. (Flaitz \& Hicks 2003).

Candidiasis has been reported as the commonest oral lesion in several studies and has been used as a clinical marker of the disease as the frequency of oral candidiasis usually correlates with a falling CD4+ $\mathrm{T}$ lymphocyte count and a rising HIV viral load Pseudomembranous candidiasis remains the commonest variant, followed by erythymatous candidiasis and angular cheilitis. Studies indicate that oral candidiasis is prevalent in HIV/AIDS and has been reported in up to $72 \%$ of all pediatric HIV infection. (Flaitz \& Hicks 2003; Kline 1996; Naidoo \& Chikte 2004; Obileye 2006; Olaniyi \& Sunday 2005; RamosGomez et al 1999; Sowole et al., 2009). However, oral pseudo-membranous candidiasis is not uncommon in healthy infants in the first six months of life. However, in immuno-competent children, Candida lesions are often mild, readily amenable to treatment, or regress spontaneously and are rarely seen beyond infancy in the absence of predisposing factors. In addition, concurrent oral infection is the most common clinical presentation of oesophageal candidiasis, a very debilitating and symptomatic AIDS-defining condition in children. (Chiou et al., 2000) Candida albicans was the primary aetiological agent but recently other species including C. tropicalis, C. krusei, C. glabrata, C. parasilosis, C. pseudotropicalis, C. gulliermondi, have been identified. C. dubliniensis, a newly emerging pathogen. isolated almost exclusively in HIV infected and oncology patients has been identified. (Brown et al 2000).

Clinical features of candidiasis are variable depending on the form of the disease. The different forms associated with HIV

infection are:

\subsubsection{Pseudomembraneous candidiasis or thrush}

This presents as non-adherent multifocal, creamy white to yellow papules or plaques overlying the oral mucosa. Removal of this material often leaves an erythematous mucosal surface, which occasionally bleeds. It typically occurs on the buccal mucosa, mucobuccal folds, dorsolateral tongue and the oropharynx, but may occur throughout the oropharyngeal region. (Flaitz \& Hicks 1999, 2003; Ramos-Gomez et al 1999). (Figures 1, 2 \& 3). 


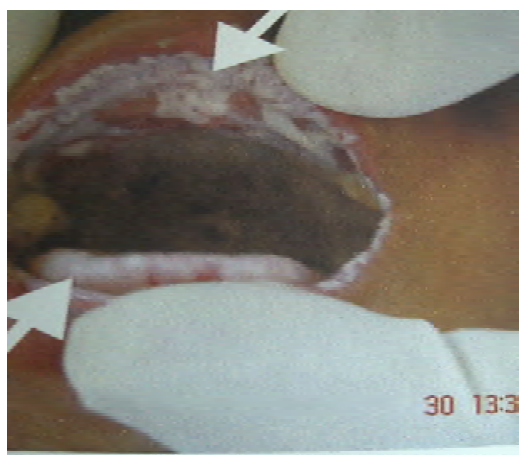

Fig. 1. Pseudomembranous candidiasis.

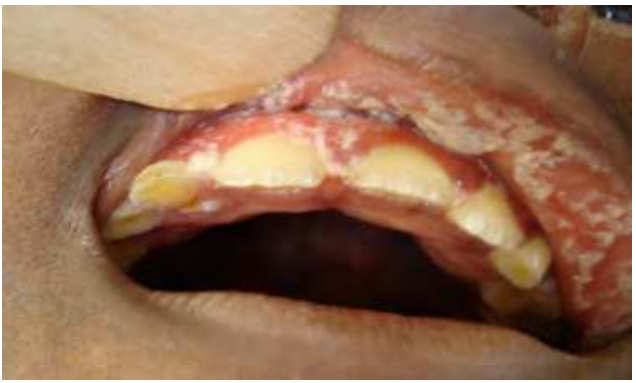

Fig. 2. Pseudomembranous candidiasis.

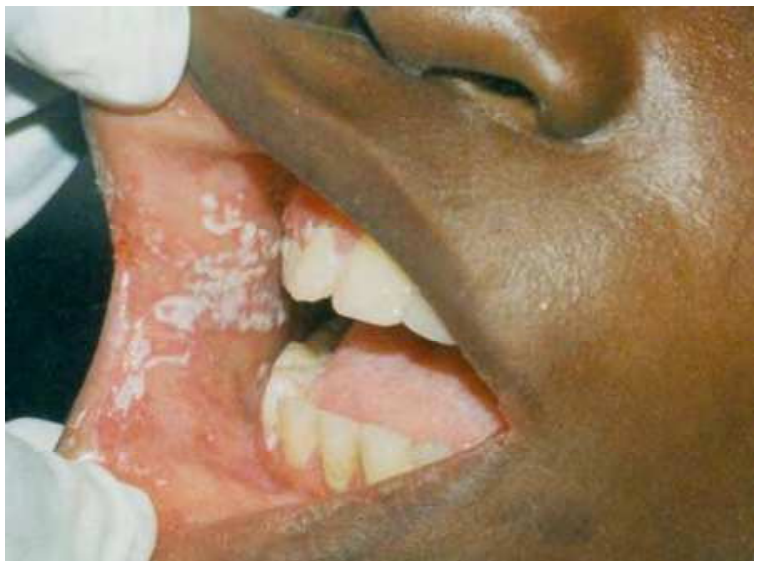

Fig. 3. Pseudomembranous candidiasis.

\subsubsection{Erythematous (atrophic) candidiasis}

This varies from diffuse to patchy redness throughout the oral mucosa. Multiple flat red patches of varying intensity occur. It sometimes presents as pinpoint to macular erythema, 
which mimics a bleeding diathesis or submucosal trauma. They are most commonly located on the palate and the dorsum of the tongue. Non adherent filmy white to creamy plaques may be seen concurrently with this lesion. When the tongue is involved, there is selective loss of filiform papillae, resulting in a red, smooth to beaded mucosal surface.

Median Rhomboid Glossitis is a specific type of erythematous candidiasis that presents as red, smooth, depapillated, persistent oral patch in the middle of the dorsum of the tongue. Tenderness or a burning sensation may be experienced. (Flaitz \& Hicks 2003; Ramos-Gomez et al 1999). (Figures 4, 5 \& 6)

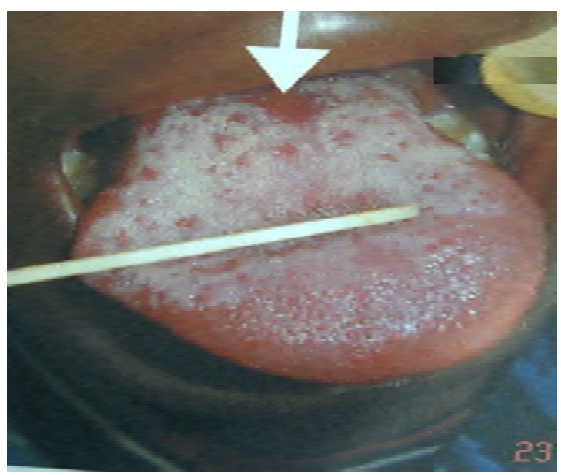

Fig. 4. Erythematous candidiasis.

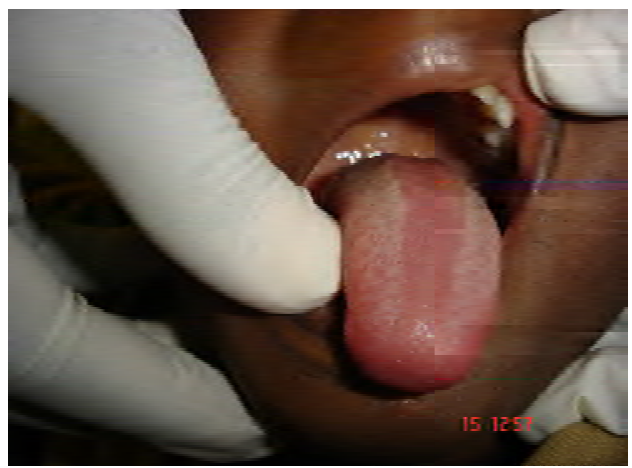

Fig. 5. Erythematous candidiasis.

\subsubsection{Angular cheilitis}

This presents as linear red or ulcerated fissures radiating from the corners of the mouth. They are typically bilateral, and multiple red papules may be found when the adjacent perioral skin is involved. (Figure 7) It commonly occurs in conjunction with either of the other intraoral forms. (Flaitz \& Hicks, 2003; Ramos-Gomez et al 1999)

\section{Diagnosis}

Definitive diagnosis of oral candidiasis is made from exfoliative cytological smears using PAS stain or potassium hydroxide or Gomori's methenamine silver stain. Detection of 


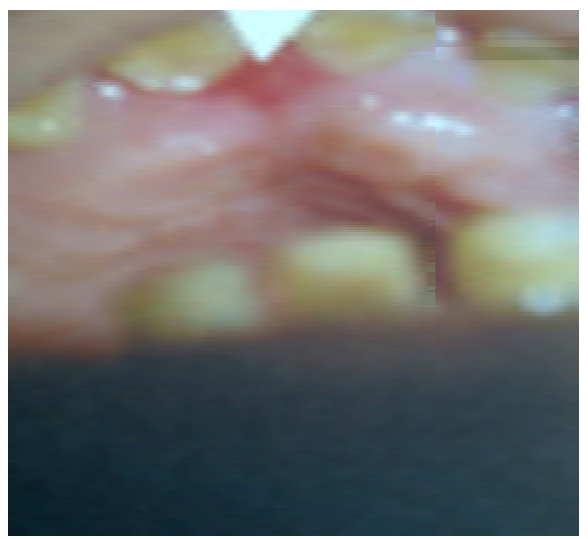

Fig. 6. Erythematous candidiasis (interdental papilla).

fungal hyphae and/or pseudohyphae is necessary for microscopic diagnosis. Biopsy of the oral lesion can also be carried out. Fungal cultures are not usually necessary but are helpful in species identification when lesions are refractory to antifungal therapy. (Flaitz \& Hicks 1999, 2003).

\section{Treatment}

Candidiasis should be treated promptly and thoroughly with topical antifungal agents such as nystatin or clotrimazole. prognosis depends on disease severity, oesophageal involvement, recurrence rate, drug compliance, the child's age and previous history and response to antifungal therapy. (Abrams 2000; Flaitz \& Hicks 1999). Both oral and esophageal candidiasis have a high propensity to recur unless antifungal therapy is continued. Therapy is indicated to prevent the symptoms of pain, burning sensation, soreness and dysphagia that may occur. (Ramos-Gomez et al.,1999)

Topical Antifungal Agents

These include Nystatin, Ketoconazole, Clotrimazole, Amphotericin B and Miconazole.

- $\quad$ Nystatin suspension $(100,000 \mathrm{U} / \mathrm{ml}) 100,000-500,000 \mathrm{U} 6$ hourly for 14days

Oral pastille $(200,000 \mathrm{U})$

- Clotrimazole troche $(10 \mathrm{mg})$

- Amphotericin B oral suspension $(100 \mathrm{mg} / \mathrm{ml})$

- $\quad$ Miconazole oral gel $(25 \mathrm{mg} / \mathrm{ml}) 2.5-5 \mathrm{ml}$
6 hourly for 14 days

10mg 4-5 times daily for 14 days $100 \mathrm{mg} 6$ hourly for 14 days 6 hourly for 14 days

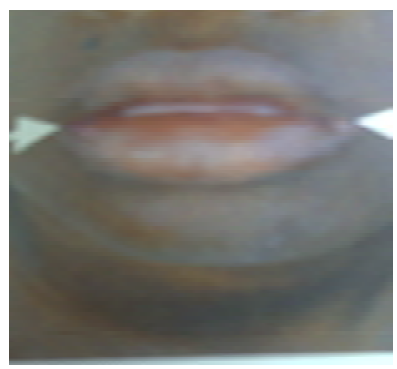

Fig. 7. Angular cheilitis. 
The long term use of these preparations may lead to increased incidence of caries because of their high dextrose or sucrose content. Topical fluoride should thus be prescribed. Alternatively, antifungal preparations designed for vagina use such as pessaries which contain less dextrose and sucrose may be used. (Greenspan 1994).

Topical creams and ointments containing Nystatin, ketoconazole or Clotrimazole are used in the treatment of angular cheilitis and peri-oral skin or lip involvement. These are applied 3 times daily. Angular cheilitis frequently occurs as a mixed infection with staphylococcus aureus, therefore an antibacterial ointment such as mupirocin may be indicated. A combination of a low potency steroid ointment and an antifungal is valuable when deep fissures and cracks on the lips are present. (the middle of the dorsum of the tongue. Tenderness or a burning sensation may be experienced. (Abrams 2000; Flaitz \& Hicks 1999, 2003; Greenspan 1993, 1994). Generally, antifungal therapy should be continued 1 to 2 weeks after clinical resolution of the lesions.

Systemic Antifungal Agents

These include Ketoconazole, Fluconazole and Itraconazole.

- Ketoconazole tablets (200mg/tablets) $5-10 \mathrm{mg} / \mathrm{kg}$ in 1 or 2 doses for 14 days

- Fluconazole suspension (50 or $200 \mathrm{mg} / 5 \mathrm{ml}) 3-6 \mathrm{mg} / \mathrm{kg}$ once daily to a maximum of $100 \mathrm{mg}$ for 14 days

- Fluconazole tablets (50 or $150 \mathrm{mg} / \mathrm{tab}$ )

- as above-

- Itraconazole caps (100mg/cap)

- Itraconazole oral liquid $(10 \mathrm{mg} / \mathrm{ml})$

$2-5 \mathrm{mg} / \mathrm{kg}$ once daily for 14 days

- as above-

In cases of drug resistant candidiasis, microbiologic culturing may be important but Fluconazole and Itraconazole have been found to be more effective empirically for treating lesions resistant to other polyenes and azoles and are associated with longer disease free periods. Suppressive maintenance antifungal therapy is indicated when frequent episodes are encountered. (Flaitz \& Hicks 1999, 2000)Disinfection and/or replacement of contaminated oral pacifiers, toothbrushes and orthodontic appliances should be done as these contribute to disease recurrence in children. Restoration of carious teeth and continuous caries prevention is important, as it has been shown microscopically that deep dental caries may act as a reservoir for Candida species in HIV infected individuals.

(Jacob et al 1998)

Recommended Prophylaxis Regimen (Flaitz \& Hicks 1999)

Nystatin oral suspension

Clotrimazole

100,000 to 400,000 units twice daily

Fluconazole

Chlorhexidine mouth rinse

$10 \mathrm{mg}$ twice daily

$6 \mathrm{mg} / \mathrm{kg}$, once daily or weekly

twice daily

\subsection{Herpes simplex virus infection}

This is the most common viral muco-cutaneous disease affecting HIV-positive children. The majority of oral lesions are caused by herpes simplex virus type1 (HSV-1). Prevalence ranges from $2 \%-24 \%$ in Paediatric HIV studies. HIV positive children who have two or more herpetic infection episodes within 1year are classified as having moderately symptomatic HIV disease. (Caldwell et al., 1994). There are 2 clinical forms:

\subsubsection{Primary herpetic gingivostomatitis}

This is a systemic viral infection which presents with sudden onset of fever, swollen and tender cervical lymph nodes, irritability and malaise. Classically, there is widespread 
mucosal erythema, vesicles and painful coalescing ulcers. The gingiva, palate, dorsum of tongue, lip and the peri-oral skin are the commonest sites (Figures $8 \& 9$ ). Excessive drooling of saliva and pharyngitis often accompanies this infection. Resolution usually occurs within 14days but the disease may linger for several more weeks in immuno-compromised children. (William1993).

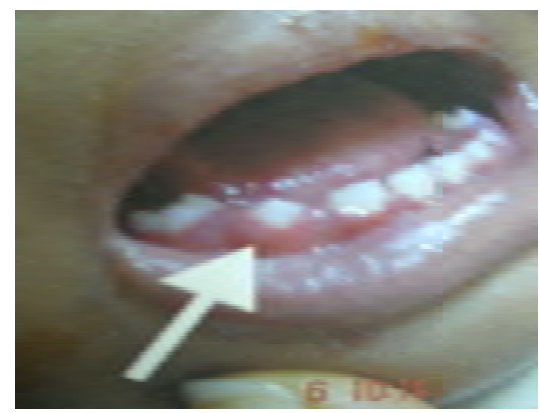

Fig. 8. Primary herpetic gingivostomatitis.

\subsubsection{Recurrent herpes simplex virus infection}

This occurs when the Herpes simplex virus is reactivated within the trigeminal ganglion by factors such as excessive exposure to sunlight, physical injury, febrile systemic illness, immunosuppression, emotional stress and hormonal alterations. It is characterized by sudden onset of focal erythema, clustered vesicles and painful coalescing ulcers. The ulcers usually involve the vermilion border of the lip, peri-oral skin, and nasal mucosa and may form crusts extraorally. Intraorally, the gingivae and palatal mucosa are usually involved. Lesions typically heal within 7 - 10days.

In immuno-suppressed children, lesions may be multifocal in distribution and occur on nonkeratinized mucosa. The infection may run a chronic course, lasting 4 - 6weeks and producing large crater form lesions with irregular serpentine to scalloped margins. Extraoral vesicular to crusted lesions that bleed on manipulation are characteristic. Deep persistent lesions may result in significant scarring. Cytomegalovirus co-infection has been observed in these persistent ulcers. (Flaitz et al., 1996).

Some HIV and other immuno-compromised children develop an unusual disease pattern on the dorsum of the tongue called the geometric herpetic glossitis. This variant appears as multiple painful ulcerated fissures that radiate from the middle of the dorsum of the tongue. Herpetic lesions recur frequently in severe immunosuppression.

Diagnosis of herpes simplex viral infection is usually clinical but can be confirmed in atypical lesions by exfoliative cytology, incisional biopsy or tissue culture with viral isolation or presence of viral giant cell. Immuno-cytochemical and fluorescent monoclonal antibody typing can be performed on direct smears, biopsy samples, or infected cells grown in tissue culture for more accurate diagnosis. (Flaitz \& Hicks 1999).

\subsubsection{Treatment}

Most herpetic lesions in HIV infected children are reported to be self-limiting. Antiviral therapy is recommended in moderately to severely immuno-compromised children and in cases with frequent recurrences. Oral acyclovir is most frequently used. Lesions resistant to 
acyclovir have been effectively managed with Foscarnet (Trisodium phosphonoformate hexahydrate).

Acyclovir $200-400 \mathrm{mg}$ tabs

6 hourly for 10-14days

Foscarnet $24-40 \mathrm{mg} / \mathrm{kg}$

8 hourly (very severe cases only) for 14-21days.

Suppressive maintenance therapy may be indicated for children who develop multiple episodes. (Ramos-Gomez et al., 1999)

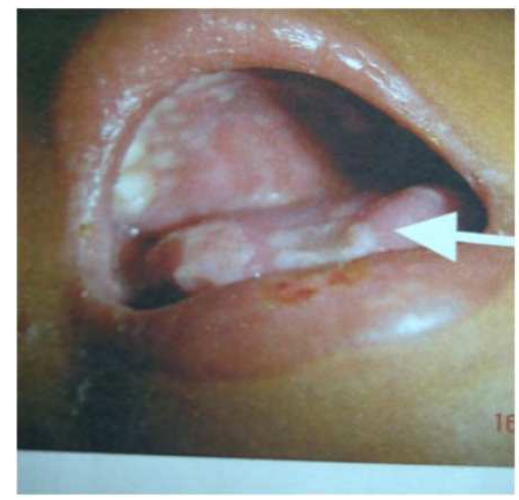

Fig. 9. Primary herpetic gingivostomatitis.

\subsection{Linear gingival erythema (LGE)}

LGE is the most common form of HIV associated periodontal disease in HIV infected children. (Kline 1996, Ramos-Gomez et al 1999). The prevalence of LGE varies widely in different studies, ranging from $0-38 \%^{2}$. However, it appears to be more common in cohorts of adolescents aged 13-18 years than in younger children. (Barasch et al 2000; Howell et al 1996).

LGE presents as a fiery red, linear band $2-3 \mathrm{~mm}$ wide on the marginal gingival accompanied by petechiae-like or diffuse red lesions on the attached gingival and oral mucosa. (Figure 10) The erythema may be accompanied by bleeding during brushing and in severe cases by spontaneous bleeding. It is most notable on the buccal surfaces from cuspid to cuspid. Pain is rarely an associated finding in most of these cases. (Ramos-Gomez et al 1999). The degree of erythema is disproportionally intense compared with the amount of plaque that is present on the teeth. (Flaitz \& Hicks 1999).

\section{Treatment}

Appropriate antifungal treatment is recommended because LGE represents an erythematous form of candidiasis. It is important to exclude neutropenia, thrombocytopenia, and plasma cell gingivitis in children with this condition. (Velegraki et al 1999).

There are no known criteria for definitive diagnosis of LGE but it resists conventional plaque removal therapies and oral hygiene measures and this distinguishes it from acute marginal gingivitis. LGE is now described as a candidal infection. Though the microbiology of LGE has not been fully described, C. albicans and C. dubliniensis have been isolated from LGE lesions in both children and adults. (Flaitz \& Hicks 2003; Ramos-Gomez et al 1999; Velegraki et al 1999). 


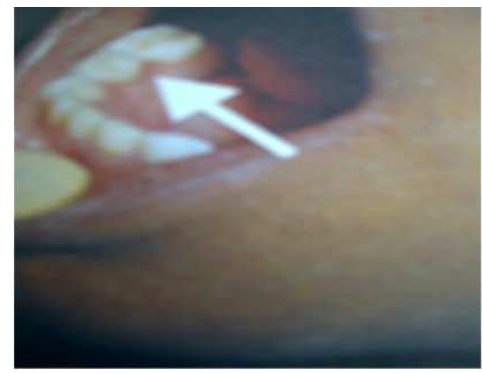

Fig. 10. Linear gingival erythema.

\subsection{Major salivary gland enlargement}

Salivary gland disease in HIV infected children presents as either xerostomia or major salivary gland enlargement. Major salivary gland enlargement refers to lymphocyte mediated salivary gland disease in cases of HIV infection. It may affect the parotid and/or submandibular glands. It was first seen in paediatric HIV infection. It is also called Diffuse Infiltrative Lymphocytosis syndrome or Sjogren syndrome-like disease. (Flaitz \& Hicks 2003). (Figure 11).

Major salivary gland enlargement is more common in children than in adults with HIV infection and the prevalence in HIV infected children varies widely in different studies with up to $58 \%$ of them being affected. The aetiology of major salivary gland enlargement is unknown but infection with EBV or HIV or the interaction between these two viruses is suspected to be responsible. (Flaitz \& Hicks 2003; Fonseca et al., 2000; Katz et al., 1993; Valdez et al., 1994).

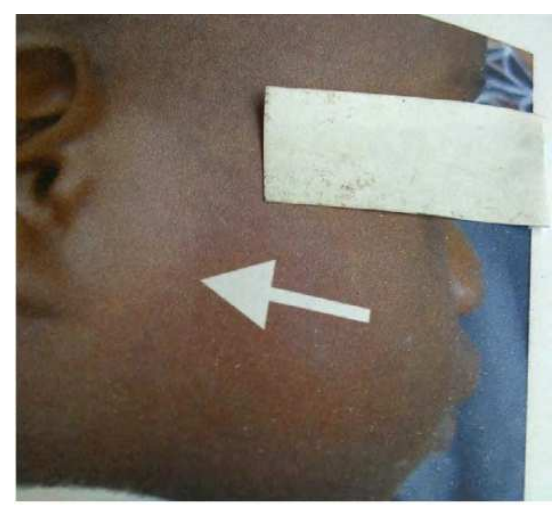

Fig. 11. Parotid gland enlargement.

The parotid gland is most commonly affected with parotid swelling in $10-30 \%$ of HIV infected children. There is unilateral or bilateral diffuse soft tissue swelling resulting in facial disfigurement. It is sometimes painful, and may be associated with lymphoid interstitial pneumonitis and diffuse lymphadenopathy. There may be concurrent enlargement of the palatine tonsils, resulting in partial airway obstruction, difficulty with swallowing and sleep apnoea. Parotid swelling has been associated with slower progression 
to AIDS: having a median time to death of 5. 4years as against 3. 4years among patients with oral candidiasis. (Chetty et al., 1999; Flaitz \& Hicks 2003; Katz et al., 1993; Ramos-Gomez et al 1999).

There are no established criteria for the definitive diagnosis of salivary gland enlargement (SGE) and the exact pathophysiology remains uncertain. Theories concerning the origin of SGE include lymphoepithelial lesions, cysts involving salivary parenchyma, interglandular lymph nodes, and an inflammatory infiltrate similar to Sjogren's syndrome. Greenspan described the possible relationship between SGE and T-lymphocyte CD8+ cell infiltration in the gland. In addition, genetic loci have been linked to SGE in children, specifically HLADR5 and HLA-DR11, suggesting a genetic predisposition to this condition. (Greenspan \& Greenspan 1996; Pinto\& De Rossi 2004)

\section{Treatment}

Salivary gland swelling is usually left untreated because it is usually asymptomatic. However, there are a number of dental management concerns and serious complications in children related to infections of the salivary glands becoming life threatening at a faster rate than in adults. The paediatric dentist should be aware of the possible complications in the paediatric HIV/AIDS population. Often the salivary gland disorders or their potential sequelae can be a predictor of HIV disease progression. Consultation with the child's infectious disease provider, including ordering complete blood counts, should give an indication of the child's immune status. Assessment of salivary function should be performed at the initial dental exam. Subjective complaints of dryness in children are often equivocal, so the clinician should be familiar with examination of the Stensen's and Wharton's ducts to verify flow. Palpation of the major glands and milking of the major glands should be a standard part of the comprehensive head and neck examination of the HIV Positive paediatric patient.

Salivary gland disease can present as benign enlargement with or without xerostomia, xerostomia alone, or parotitis or more ominous conditions such as malignancy. In children, serious complications related to salivary gland infections can become life-threatening at a faster rate than in adults. The clinician should be aware of the etiologic agents that can cause parotitis (bacterial/viral). Knowledge of the child's immune status will often serve as a guide towards diagnosis (i. e., cytomegalovirus or paramyxovirus in immune-compromised children). Thorough examination of salivary ducts can provide valuable information on aetiology-(purulence in saliva, thick mucous saliva) and guide the clinician to adequate treatment. The antibiotic of choice is clindamycin, in a dosage of $8-25 \mathrm{mg} / \mathrm{kg} /$ day. A therapeutic alternative antibiotic is penicillin, considering the gastrointestinal effects of clindamycin. (Pinto\& De Rossi 2004).

\subsection{Recurrent aphtous ulcers (RAU)}

The prevalence of RAU in HIV infected children ranges from $0-7 \%$ similar to HIV infected adults. In general RAU tend to recur more frequently in the HIV infected child; and with immunosuppression, major aphthous ulcers are also more likely to develop. (Flaitz \& Hicks 2003).

RAU presents as painful ulcers of rapid onset with marked predilection for non keratinised mucosa especially the labial and buccal mucosa, ventral tongue and soft palate. The pharyngeal and oesophageal mucosa may be involved in the most extensive cases. Three clinical varieties have been described based on size, number and duration of lesions present. 


\subsubsection{Minor recurrent aphthous ulcers}

This presents as 1-3 shallow, oval or round small ulcers less than $5 \mathrm{~mm}$ in diameter covered with a pseudo membrane surrounded by an erythematous halo. (Figure 12). They are self limiting and typically heal within 2weeks without scarring. (Flaitz \& Hicks 2003; RamosGomez et al 1999).

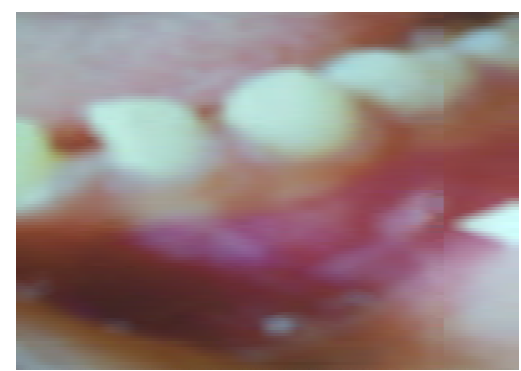

Fig. 12. Minor Aphthous Ulcer.

\subsubsection{Major recurrent aphthous ulcers}

These are oval or round, similar to minor recurrent aphthous ulcers but much larger $1-2 \mathrm{~cm}$ in diameter, are fewer in number, and may persist for weeks at a time. They are painful and may interfere with mastication and swallowing. They tend to occur on the soft palate, buccal mucosa, tonsillar area, and tongue. They have well delineated to irregular borders and depressed bases and are often covered by a thick, tenacious, fibrinous exudate. Scaring is a common finding in this condition.

\subsubsection{Herpetiform recurrent aphthous ulcers}

These appear as clusters or crops of tiny recurrent aphthous ulcers, 1 to $2 \mathrm{~mm}$ in diameter, which may coalesce. They tend to occur in the soft palate, buccal mucosa, tonsillar area, and tongue. Diagnosis is usually clinical, based on the size, site, appearance and duration of the ulcers.

A definitive criterion for all three types of RAU is the response to treatment with steroid agents. Tissue cultures for viral, fungal and mycobacterial organisms and incisional biopsy are necessary for persistent lesions to rule out other causes of ulcers. (Flaitz \& Hicks 2003; Ramos-Gomez et al 1999).

\subsubsection{Treatment}

A definitive criterion for all the three types is the response to treatment with steroid agents. Tissue cultures for viral, fungal and mycobacterial organisms and incisional biopsy are necessary for persistent lesions to rule out other causes of ulcers. Topical steroid therapy is the first choice. In severe cases, a short course of prednisolone is indicated. Antifungal agents to prevent oropharyngeal candidiasis are added when steroids are used. These steroids include fluocinomide, clobetasol propionate and dexamethasone elixir. (RamosGomez et al 1999). 


\section{Oral lesions less commonly associated with paediatric HIV infection}

\subsection{HIV associated periodontal diseases}

These include:

- $\quad$ Necrotising ulcerative gingivitis (NUG)

- $\quad$ Necrotising ulcerative periodontitis (NUP)

- $\quad$ Necrotising stomatitis (NS)

In children, HIV associated periodontal diseases appear to be associated with both immunodeficiency and malnutrition ${ }^{4}$. HIV infected children from developing countries appear to be more susceptible to necrotising periodontal diseases. A declining immune system with CD4 + cell counts below 200 cells/mm is associated with necrotising ulcerative periodontitis and necrotising stomatitis. (Flaitz \& Hicks 2003; Greenspan 1994; RamosGomez et al 1999).

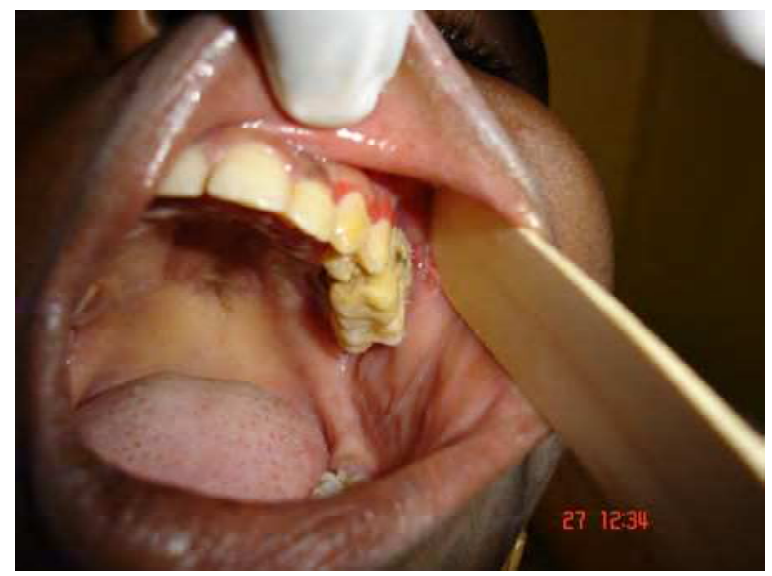

Fig. 13. Necrotising Ulcerative Periodontitis (NUP).

\subsubsection{Necrotising ulcerative gingivitis (NUG)}

This is uncommon in HIV infected children. It is reported to present with the destruction of one or more interdental papillae accompanied by necrosis, ulceration and/or sloughing. Destruction is limited to the marginal gingival tissues. In the acute stage, the gingival tissues appear fiery red and swollen, and is accompanied by yellowish grey necrotic tissue that bleeds easily. Patients are reported to experience bleeding on brushing, pain and a characteristic halitosis. Symptoms subside gradually over 3 - 4 weeks but recurrences are common.

There may be lymphadenopathy, fever and malaise. Permanent gingival scarring with interdental papillary crater contributes to an increased risk of recurrence. (Flaitz \& Hicks 2003). Diagnosis is based on clinical features described above.

\subsubsection{Necrotising ulcerative periodontitis (NUP)}

NUP has been reported in $0-4 \%$ of children. It presents as severe soft tissue necrosis along with destruction of the periodontal attachment and bone over a short period of time. Patients often experience spontaneous gingival bleeding or bleeding when brushing and severe, deep, aching pain in the jawbone. The jawbone may be exposed in the most severe 
cases. The final stage of NUP is marked by severe gingival recession resulting from rapid bone loss and soft tissue necrosis. (Figures 13 \&14) Pocketing may be minimal and tissue destruction may extend across the mucogingival junction. The more extensive disease may contribute to premature exfoliation of primary teeth and aborted development or early loss of primary teeth. (Flaitz \& Hicks 2003; Ramos-Gomez et al 1999). Diagnosis of NUP is based on clinical presentations.

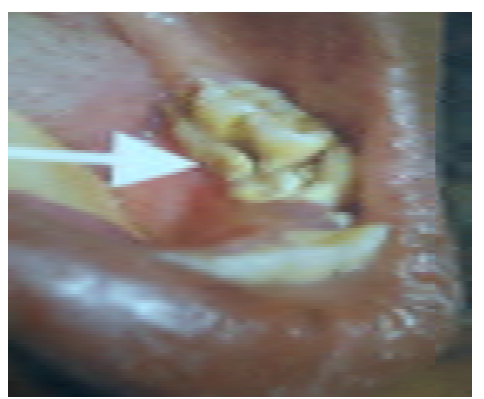

Fig. 14. Necrotising Ulcerative Periodontitis (NUP)

\subsubsection{Necrotising stomatitis (NS)}

This presents as an acute and painful ulceronecrotic lesion on the oral mucosa. The lesion starts from the oral mucosa and may extend to alveolar bone and contiguous soft tissues. The underlying bone may be exposed. Histologic examination reveals the features of nonspecific ulceration. No specific microbial organism has been identified as the cause of NS. (Flaitz \& Hicks 2003; Ramos-Gomez et al 1999).

\subsubsection{Treatment for NUG, NUP and NS}

\section{Local treatment}

- Gentle debridement of affected areas to minimize bleeding and pain

- Irrigation with $10 \%$ Betadine providone -iodine or 1:4 hydrogen peroxide or Chlorhexidine gluconate (Peridex), $0.12 \%$ to aid debridement.

- Oral hygiene instruction

\section{Systemic Treatment}

- $\quad$ Metronidazole (Flagyl) $125 \mathrm{mg}$ tablets 8hourly for 7days

- Amoxicillin (Amoxil) $250 \mathrm{mg}$ 8hrly for 7days

If the patient is allergic to penicillin:

- $\quad$ Erythromycin enteric coated 250mg tablet 8hourly for 7 days

The patient should be re-evaluated after one week of treatment and the medication should be repeated if response is not satisfactory.

Supportive therapy: Multivitamins

\subsection{Viral infections}

\subsubsection{Human Papilloma Virus}

Human Papilloma Virus (HPV) induced oral lesions associated with HIV infection include Verucca vulgaris, condyloma acuminatum, focal epithelial hyperplasia, and koilocytic 
dysplasia which are referred to as oral warts. Oral HPV infections are rare in children. Oral warts present as raised, irregular, flesh coloured lesions.

\subsubsection{Focal epithelial hyperplasia (Heck's disease)}

This is a benign condition associated with HPV types 13 and 32 and is usually seen in children. The lesions appear as multiple, non-tender papules, plaques or nodules with grainy pink mucosal surfaces. The labial, buccal and lateral tongue, mucosa are most often involved, with occasional lesions on the palatal and gingival mucosa. (Figure 15).

\section{Treatment}

In most cases, conservative excision is treatment of choice. Other methods of treatment include laser ablation, topical podophyllin resin, systemic interferon, and cimetidin. Despite aggressive therapy and multiple treatment modalities, recurrences are common when oral warts are widespread. (Flaitz \& Hicks 2003; Howell et al 1996; Ramos-Gomez et al., 1999).

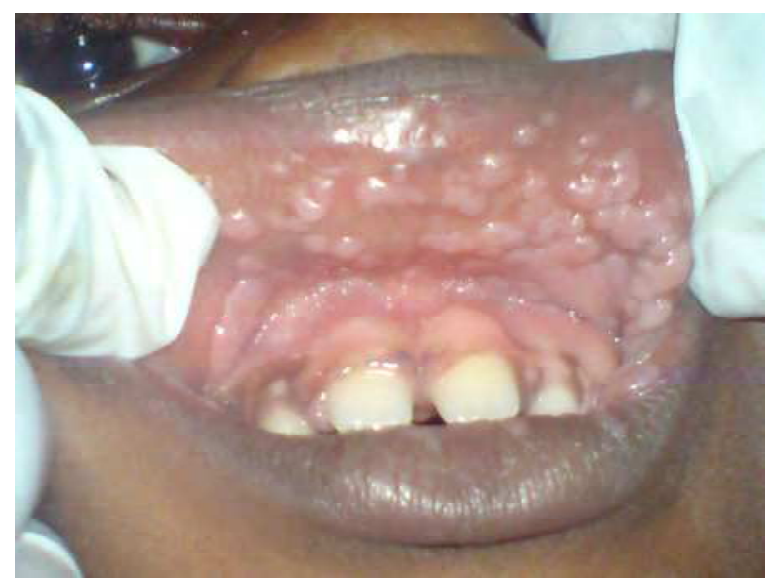

Fig. 15. Focal Epithelial hyperplasia (Heck's disease).

\subsubsection{Verruca vulgaris}

This typically affects the skin, especially the hands and perioral skin. Oral mucosal involvement due to inoculation from these extraoral sites. Intraoral involvement is uncommon and is usually limited to isolated areas of the lip vermillion, labial mucosa and anterior tongue. They present as white, rough, conical or papillary papules or nodules. Treatment is as for Focal Epithelial Hyperplasia above.

\subsubsection{Condyloma acuminatum}

It typically presents as a large sessile, pink nodule with short, blunt surface projections. Multiple lesions may be found that tend to coalesce, forming a discrete, well-delineated enlargement. Diagnosis is usually clinical. Definitive diagnosis can be made by excisional biopsy.

Treatment is as for Focal Epithelial Hyperplasia and oral warts. 


\subsubsection{Cytomegalovirus (CMV)}

This presents as a persistent oral ulcer, which may mimic aphthous ulcers, recurrent herpes simplex virus infection, necrotising stomatitis and ulceration not otherwise specified. Occasionally it may present as a brightly erythematous gingivitis. CMV ulcers in the oral cavity usually occur with disseminated CMV disease; therefore the patient should be examined for the systemic disease or other organ involvement including CMV retinitis, colitis, pneumonitis and progressive neurologic disease. Definitive diagnosis can be made through culture and biopsy. (Flaitz et al., 1996; Ramos-Gomez et al., 1999).

\subsubsection{Varicella Zoster Virus (VZV)}

VZV infection can present as Herpes Zoster or Varicella (chicken pox). HIV infected children are at risk for persistent, recurrent, chronic infections with VZV. Children with advanced immunosuppression seem to be at increased risk for recurrent disease and more severe manifestations of VZV. Chronic VZV infection has been described in HIV-infected children and adults with low CD4+ counts. (Gershon et al., 1997; Morris et al., 1996; Ramos-Gomez et al., 1999).

\subsubsection{Herpes Zoster}

The Center for Disease Control and Prevention has classified an HIV-infected child with herpes zoster involving at least 2 distinctive episodes or more than one dermatome as being moderately symptomatic. Herpes Zoster infection results from a reactivation of latent varicella - zoster virus. Fevers, complaints of sensitive teeth, earache or headache as well as pain or paresthesia are prodromal symptoms. A well-delineated unilateral maculo-papular rash that becomes pustular ulcerated follows. Involvement of the second and third branches of the trigeminal nerve produces oral lesions on both keratinised and non keratinsed oral mucosa that extend to the midline. Frequently concurrent vesicles and crusted skin lesions overlie the affected dental quadrant. Most cases heal without complications in children except for facial skin scarring. Definitive diagnosis is by virus antigen typing with laboratory immunologic tests. (Caldwell et al., 1994; Flaitz \& Hicks 2003; Ramos-Gomez et al 1999).

\subsubsection{Molluscum contagiosum}

This is a virally induced lesion of the skin, vagina, and rarely, the oral cavity. Lesions are small, discrete, and dome shaped. Their colour ranges from pearly white to skin colour. The lesions may number in the hundreds. Definitive diagnosis is made when molluscum bodies, which are virally transformed epithelial cells are seen, when the core of the lesion is expressed and stained.

(Ramos-Gomez et al 1999).

\subsection{Xerostomia}

Xerostomia is a common symptom of HIV-infected individuals and has many potential causes.

It is more common in HIV infected children than HIV-infected adults. The causes of xerostomia include HIV infection itself, therapeutic antiviral and antimicrobial drugs, prophylactic medications, antiretrovirals (such as didanosine), gamma globulin, or lymphocytic infiltration of the major salivary glands. Clinical features include dry mouth (Figure 16) and severely reduced salivary flow rates. Reduced salivary flow results in a 
mucosa that is desiccated and is at higher risk for opportunistic infections such as candidiasis and increased caries. Xerostomia may appear with or without parotid swelling. No definitive diagnostic criteria exist for xerostomia. (Flaitz \& Hicks 2003; Frezzini et al., 2006; Ramos-Gomez et al 1999).

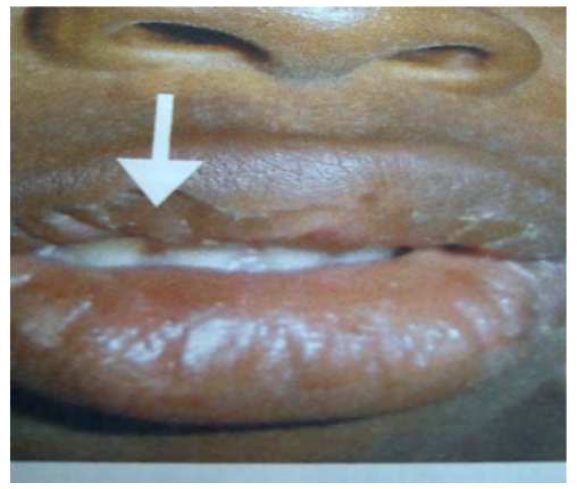

Fig. 16. Dry lips with crusting, resulting from xerostomia.

\section{Oral lesions strongly associated with HIV infection but rare in children}

\subsection{Kaposi's sarcoma}

This is much less common in HIV infected children than adults. The incidence of HIV associated cancers in symptomatic children is less than $2 \%$. However, among HIV infected paediatric population, it is more common in Africa, Latin America and Eastern Europe, where endemic Kaposi's sarcoma is more prevalent in the non-HIV infected population. Human herpes virus -8 has been identified in all forms of Kaposi's sarcoma. (Flaitz \& Hicks 2003; Ramos-Gomez et al 1999; Ranganathan \& Hemalatha 2006). Kaposi's sarcoma presents as one or more erythematous, slightly bluish or violaceous macules or swellings with or without ulceration. It is predominantly seen on the palate or gingiva. A definitive criterion is characteristic histologic appearance on biopsy. (William 1993).

\subsection{Non-Hodgkin's lymphoma}

This is far less common in HIV infected children than adults. This presents as a firm, elastic often somewhat reddish or purplish swelling with or without ulceration. The gingiva, palatal mucosa and fauces are more commonly affected. A definitive criterion is the characteristic histological appearance on biopsy, supported by appropriate immuno-cytochemical or molecular biological investigations. (Ramos-Gomez et al 1999; William 1993).

\subsection{Oral Hairy Leukoplakia (OHL)}

This is an opportunistic infection caused by the Epstein-Barr virus (EBV) and is a marker for increasing immunodeficiency. It is a common oral manifestation of HIV infection in adults with a point presence of approximately $20 \%$ but it is documented in only $2 \%$ of children infected with HIV. It presents as white non-removable lesions with corrugated surface appearing bilaterally on the lateral border of the tongue. These lesions may appear on the ventral and dorsal surfaces of the tongue and more rarely, on the buccal mucosa. Definitive 
criteria for oral hairy leukoplakia are the presence of Epstein -Barr virus (EBV) in the lesions, to be determined by laboratory histopathology and in-situ DNA hybridization. (Flaitz \& Hicks 2003; Morris et al., 1996; Ramos-Gomez et al 1999).

\subsection{Tuberculosis related ulcers}

A combined infection with HIV and mycobacterium tuberculosis is common in LINCs and developing countries. However, secondary and primary tuberculosis lesions of the oral cavity are rare. The lesions present as painless, non-healing ulcerations on the buccal mucosa, hard palate, gingivae and/or tongue. Occasionally, tuberculosis may present with tongue involvement manifesting as macroglossia or a mass in the cheek. In most cases the mucosal lesions are difficult to recognize, but enlarged regional lymph nodes may call attention to the process.

A chest radiograph and a Purified Protein Derivative test with appropriate controls should be obtained. Diagnosis is usually confirmed by identification of acid-fast bacilli in tissue sections or culture. The oral lesions respond to treatment with use of anti-tuberculosis drugs. (Ceballos-Selobrena et al., 1996; Grupta et al., 1997; Hathiram et al., 1997; Haller \& Ginsberg 1997; Kolokotronis et al., 1996; Ramesh 1997; Phelan et al., 1997; Ramos-Gomez et al 1999).

\section{Oral conditions with increased severity in paediatric HIV infection}

\subsection{Gingivitis and periodontitis (increased gingival and plaque indices)}

Gingival disease not specifically associated with HIV infection is called conventional gingivitis. Reported prevalence in HIV infected children is $7 \%$ and $40 \%$. Clinically, it presents as gingival inflammation in the absence of attachment loss, necrosis or gingival erythematous banding.

(Barasch et al., 2000; Gelbier et al., 2000). An association between the prevalence of gingivitis in HIV infected children and age has been reported. (As low as 6\% in less than 1 year olds, $55 \%$ in 1 year olds, $85 \%$ in 2 year olds, $87 \%$ in 3year olds and $66 \%$ in 4 year olds). (Ramos et al., 2000).

\subsection{Over retained primary teeth and delayed eruption of primary and permanent teeth}

Delayed eruption of teeth has been reported among children with HIV-infection. Poor general health in some children may be an associated factor. Delayed tooth development has been reported in $31 \%$ of paediatric AIDS patients. (Valdez et al 1994). Delayed dental development in paediatric HIV patients has been linked to lower CD4 counts. In the report by Ramos-Gomez et al 2000; it was observed that at age 3, there was an average of two fewer teeth per child among children whose average CD4 count was $200 / \mathrm{mm}^{3}$ than children whose average CD4 count was $800 / \mathrm{mm}$. A study on $173 \mathrm{HIV}$ infected children, delayed eruption was reported in $43 \%$ males and $41 \%$ females. Accelerated eruption in $11 \%$ males and $13 \%$ females, while $46 \%$ of both males and females have normal eruption pattern. Over retained primary teeth was observed in $25 \%$ of the children. (Flaitz et al., 2000).

\subsection{Dental caries}

There is anecdotal evidence of vulnerability of HIV infected children to dental caries. However, some researchers have drawn attention to comparable caries prevalence in 
infected and non-infected children. Other studies have shown slightly higher prevalence of dental caries in children with HIV. The suggestion that caries development could be directly linked to immunosuppression is yet to be substantiated, although the possibility does exist. Other factors may be responsible for the high caries level in these children, and these include infant feeding practices, the long term use of sugar containing medicines, high consumption of carbohydrate and sugar intake required to prevent or treat any failure to thrive.

A number of studies have reported on the prevalence of dental caries among HIV infected children. (Elderidge \& Gallagher 2000; Flaitz et al., 2000; Gelbier et al., 2000; Hicks et al 2000; Obileye et al., 2009, Sowole et al 2009; Tofsky et al 2000; Valdez et al 1994). In a study on dental caries prevalence and dental health behavior in HIV infected children, $63 \%$ of the children had past dental caries experience. (Elderidge \& Gallagher 2000) This is similar to a previous report by Valdez et al; it was observed that $60 \%$ of paediatric AIDS patients had clinical evidence of current or past caries.

In the primary dentition of HIV infected children, the anterior caries (early childhood caries, nursing bottle or baby bottle tooth decay) pattern is common. The pattern of caries observed in this group of children may be as a result of poor oral hygiene practices, inappropriate use of a nursing bottle containing high sucrose liquids at bed time, medications containing high sucrose content, xerostomia induced by medication or HIV infection, the need for high caloric and carbohydrate/sucrose diets, and alterations in saliva viscosity, cytokines, protease inhibitors and immunoglobulin. (Flaitz \& Hicks 2003). (Figures 17 \& 18)

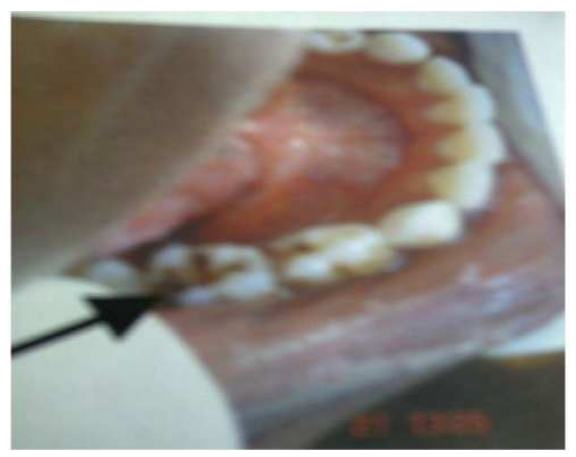

Fig. 17. Dental caries on mandibular primary molars.

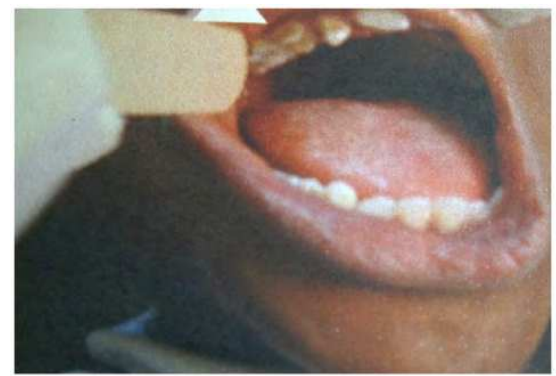

Fig. 18. Dental caries on maxillary primary canines and molars. 
Dental caries status in primary dentition of HIV infected children has been reported to be considerably greater than that for the United States paediatric population. (Hicks et al., 2000.) During the 30 month period longitudinal study, there was an almost two fold increase in primary tooth surface caries for the 2-9 year olds. Caries free status in the primary dentition declined from $60 \%$ at baseline to $37 \%$ at the 30 months period. Among 5 to 11 year olds, dmfs and $\mathrm{dmft}$ remained relatively stable while the proportion of caries free individuals declined from $72 \%$ at baseline to $50 \%$ at 18 months. Caries free status decreased with age, lower CD4 percentage and from moderate to severe immunosuppression. (Hicks et al., 2000). A high prevalence of Candida colonization in HIV positive /AIDS children with untreated dental caries has been reported. (Domaneschi et al., 2010). This further reinforces the importance of oral health care in interdisciplinary health unit that manage these patients.

Caries and periodontal disease are among the most common infections known to humans. Both are initiated by oral bacteria and are modulated by the host response. Disease occurs as a result of an imbalance between the provoking bacteria and host response. It is logical to expect, therefore, that alterations of either the associated aetiological factors or the host response to these factors and or agents should result in a change in the clinical presentation of disease. (Fine et al., 2003).

\section{Conclusions}

Oral manifestations are common and prevalent in paediatric HIV infection and have been found to be the earliest indicators of HIV infection. Early intervention in HIV disease is crucial for each individual according to his/her risk and seroconversion status. Comprehensive oral examination should be done at regular intervals especially in LINCs and developing countries where techniques to diagnose, and the drugs to treat HIV infection are not uniformly distributed. The use of oral lesions as predictors of disease progression could be of immense importance. Primary oral health care for HIV infected children should include a careful oral examination at regular intervals to ensure early detection and intervention for pseudomembranous candidiasis and other infections and to prevent more deterioration of the immune system and further opportunistic infections. Preventive oral health care especially where treatment is progression unavailable, can improve a child's overall health. Though these measures cannot stop HIV disease progression, in the absence of medications, improved diagnosis of the oral manifestations can enhance case management, ensure better oral health outcomes, reduce morbidity and improve quality of life of HIV-infected children.

\section{Acknowledgement}

The authors wish to thank the Staff of the Special Paediatric Outpatient Clinic of Lagos University Teaching Hospital and Peadiatric HIV Outpatient Clinic of Massey Children Hospital, Lagos Nigeria for their cooperation and assistance and in particular the parents and children for their consent to participate with the investigations and approval to make use of their clinical photographs.

\section{References}

Abrams EJ. (2000). Opportunistic Infections and Other Clinical Manifestations of HIV Disease in Children. Pediatr Clin North Am 47: 95 -96 
Agbelusi GA, Wright AA (2005). Oral lesions as Indicators of HIV Infection among Routine Dental patients in Lagos, Nigeria. Oral Dis 11:370-373.

Ammann AJ. (2004). Overview of Paediatric HIV Disease. In The AIDS Knowledge Base: A Textbook on HIV Disease Cohen PT, Sande MA, Volberding PA et al.,8. 11-8. 17, 2nd Edition, University of California

Ammann AJ. (2006). Handbook of Pediatric HIV Care 2nd Edition. Eds Zeicher SL, Read JS. Cambridge University Press New York NY, 2006. ISBN-10:0521529069

Arendorf (1998). Bredekamp B, Cloete CAC, Sauer G. (1998). Oral Manifestations in 600 South African Patients, J Oral Pathol Med. 27: 176-179

Barasch A., Salford MM., Catalantto FA., Fine DH \& Katz RV. (2000). Oral soft tissue manifestations in HIV-positive vs. HIV-negative children from an inner city population; a two-year observational study. Pediatr Dent. May-Jun;22 (3): 215-20

Barone R, Ficarra G, Gaglioti D, Orsi A, Mazzotta F. (1990) Prevalence of Oral Lesions among HIV-infected Intravenous Drug Abusers and Other Groups. Oral Surg Oral Med Oral Pathol 69: 169-173.

Barnett T, Whiteside A. (2006) AIDS in the twenty-first century: Disease and Globalization. 2nd edition. New York: Palgrave Macmillan; 2006. 416

Brown DM, Jabra-Rizk MA, Falker WA, Baqui AAMA, Meiler TF. (2000). Identification of Candida dubliniensis in a Study of HIV-Seropositive Pediatric Dental Patients. Pediatr Dent 2000; 22: 234 - 238

Centres for Disease Control and Prevention. (1993) Classification System for HIV Infection and Expanded Surveillance Case Definition for AIDS among Adolescents and Adults. MMWR 41:1-19.

Caldwell MB, Oxtoby MJ, Simond RJ, et al. (1994) Revised Classification System for Human Immunodeficiency Virus Infection in Children Less Than 13 Years of Age. MMWR 43: $1-10$

Ceballos-Salobrena A, Agurre-Urizar JM, Bagan-Sebastian JV. (1996). Oral Manifestations Associated with Human Immunodeficiency Virus Infection in a Spanish Population. J Oral Pathol Med 1996; 25: 523 - 526.

Chadwick \& Yogev, 1995;

Chetty R, Vaithilingum M, Thejpal R. (1999). Epstein Barr Virus Status and the Histopathological Changes of Parotid Gland Lymphoid Infiltrates in HIV-Positive Children. Pathology 1999; 31: 413 - 417

Chiou CC, Groll AH, Gonzalez CE, et al. Esophageal Candidiasis in Paediatric Acquired Immunodeficiency Syndrome. Clinical Manifestations and Risk Factors. Pediatr Infect Dis J 2000; 19: 729 - 734

Coogan MM, Greenspan J, Challacombe SJ. Oral lesions in infection with human immunodeficiency virus. Bull World Health Organ. 2005; 83:700-6.

De Cock, KM., Fowler, MG., Mercier E., de Vincenzi, I., Saba, J., Hoff, E., et al. (2000) Prevention of mother-to-child HIV transmission in resource-poor countries: translating research into policy and practice. JAMA. 2000; 283 (1175-1182).

Domaneschi C, Masserente D, De Freitas R, De Souza Marques H, Paula C, Migliari D, Antunes J (2010). Oral Clonozation by Candida species in AIDS pediatric patients. Oral Dis 2010; Nov 29 doi 1111/j. 1601-0825. 2010. 01765. x.

Elderidge K, Gallagher JE. Dental Caries Prevalence and Dental Health Behaviour in HIV Infected Children. Int J Pediatr Dent 2000; 10: 19 -26 
Fine DH, Nelson EM, Schoen D, Barasch A. (2003). Clinical implications of the oral manifestations of HIV infection in children Dent Clin N Am 2003; 47: 159-174

Flaitz C, Nichols CM, Hicks MJ. (1996). Herpes viridea-associated Persistent Mucocutaneous Ulcers in Acquired Immunodeficiency Syndrome: A Clinicopatholgic Study. Oral Surg Oral Med Oral Pathol Oral Radiol Endod 1996; 81: 433 - 441.

Flaitz CM, Hicks MJ. (1999). Oral Candidiasis in Children with Immune Suppression: Clinical Appearance and Therapeutic Considerations. J Dent Child 1999; 66 (May Jun): 161 - 166.

Flaitz CM, Wullbrandt B, Sexton J, et al. (2000). Prevalence of Orodental Findings in HIV Infected Romanian Children. Pediatr Dent 2000; 23: 44 - 50

Flaitz CM, Hicks MJ. (2003) Oral Manifestations in Paediatric HIV Infection. In: Shearer WT, Hanson IC, eds. Medical Management of AIDS in Children. USA: Elsevier Science, 2003: 248 - 269

Fonseca R, Cardoso AS, Pomarico I. (2000) Frequency of Oral Manifestation in Children Infected with Human Immunodeficiency Virus. Quintessence Int 2000; 31: 419 422.

Fowler MG, Simonds RJ, Roongpisuthipong A. (2000). Update on perinatal HIV transmission. Pediatr Clin North Am 2000; 47: 21-37

Frezzini, C. Leao, JC. Cedro, M. Porter, S. (2006). Aspects of HIV Disease Relevant to Dentistry in the 21st Century. Dent Update, 2006; 33:276-286

Gray G, McIntyre J. (1999) International AIDS Society Newsletter 1999; 178: 368-74

Gelbier M, Lucas VS, Zervou NE, Roberts GJ, Novelli V. (2000)A Preliminary Investigation of Dental Disease in Children HIV Infection. Int J Pediatr Dent 2000; 10: 13 - 18.

Gershon AA, Mervish N, LaRussa P, et al (1997). Varicella zoster Virus Infection in Children with Underlying Human Immunodeficiency Virus Infection. J Infect Dis 1997; 176: $1496-1500$

Giaquinto C, Penazzato M, Rosso R, Bernardi S, Rampon O, Nasta P, Ammassari A, Antinori G et al., (2010). Italian Paediatric HIV Infection Working Group. Italian consensus statement on paediatric HIV infection. Infection. 2010; 38(4):301-19

Glick M (2005). Orofacial disorders in children with HIV disease. Dent. Clin North Am. 2005 Jan; 49(1): 259-71, x-xi

Greene WC (2007). A history of AIDS: looking back to see ahead. Eur J Immunol. 2007; 37:S94-102.

Greenspan D, Schiodt M, Greenspan JS, Pindborg JJ. AIDS and the Mouth, Diagnosis and Management of Oral Lesions. Copenhagen: Munksgaard; 1990

Greenspan D, Greenspan JS. (1993) Oral Manifestations of Human Immunodeficiency Virus Infection. Dent Clin North Am 1993; 37 (Jan): 21 - 23.

Greenspan D. (1994) Treatment of Oral Candidiasis in HIV Infection. Oral Surg Oral Med Oral Pathol 1994; 78: 211-215.

Greenspan,JS, Greenspan D. (1995). Oral manifestations of HIV infection. Proceedings of the Second International workshop on the Oral manifestations of HIV infection. Quintessence, Carol Stream IL, 1995.

Grupta A, Shinde KJ, Bhardway I. (1997). Primary Lingual Tuberculosis: A Case Report. J Laryngol Otol 1997; 112: 86 - 87

Haller JO, Ginsberg KJ. (1997) Tuberculosis in Children with Acquired Immunodeficiency Syndrome. Pediatr Radiol 1997; 27: 186 - 188 
Hathiram BT, Grewal DS, Irani DK, Tankwal PM, Patanker M. (1997). Tuberculoma of the Cheek: A Case Report. J Larygngol Otol 1997; 111: 872 - 873

Hicks MJ, Flaitz CM, Bruce Carter A, et al. (2000). Dental Caries in HIV Infected Children: A Longitudinal Study. Pediatr Dent 2000; 22: 359 - 364

Howell RB, Jandinski J, Palumbo P, Shey Z, Houpt MI. (1996) Oral Soft Tissue Manifestations and CD4 Lymphocyte Counts in HIV-Infected Children. Pediatr Dent. 1996; 18:114-116.

Katz MH, Mastrucci MT, Leggott PJ, Westenhouse J, Greenspan JS \& Scott GB. (1993). Prognostic significance of oral lesions in children with perinatally acquired human immunodeficiency virus infection. Am J Dis Child 1993 Jan; 147(1): 45-8.

Kline MW. Oral Manifestations of Pediatric Human Immunodeficiency Virus Infection: A Review of the Literature. Pediatr 1996; 97 (Mar): 380 - 388.

Kolokotronis A, Antoniadis D, Trigonidis G, Papanagiotou P. (1996) Oral Tuberculosis. Oral Dis 1996; 2: 242 - 243

Lamster IB, Begg MD, Mitchell Lewis D et al., (1994) Oral manifestations of HIV Infection in Homosexual Men and Intravenous Drug Users. Study Design and Relationship of Epidemiologic, Clinical and Immunologic parameters to Oral Lesions. Oral Surg Oral MedOral Pathol 1994; 78:163-174

Leao JC, Ribeiro CM, Carvalho AA, Frezzini C, Porter S. (2009) Oral complications of HIV disease Clinics (Sao Paulo) 2009; 64(5) : 459-70.

Magalhaes MG, Bueno DF, Serra E, Gonclaves R. (2001) Oral manifestations of HOIV positive children. J Clin Pediatr Dent 2001; 25(2): 103-106

Massarente, DB. Domaneschi, C. Marques, HH. Andrade, SB. Goursand, D \& Antunes, JL. (2011). Oral health-related quality of life of paediatric patients with AIDS. BMC Oral Health. 2011; 5; 11:2.

Morris CR, Araba-Owoyele L, Spector SA, et al. (1996). Disease Patterns and Survival After Acquired Immunodeficiency Syndrome Diagnosis in Human Immunodeficiency Virus Infected Children. Pediatr Infect Dis J 1996; 15: 321

Naidoo S, Chikte U (2004). Orofacial manifestations in paediatric HIV: a comparative study of institutionalized and hospital outpatients. Oral Dis 2004;10: 13-18

National AIDS and STD Control Program Federal Ministry of Health and Social Services in Collaboration with Nigeria Medical Association. Handbook of HIV Infection and AIDS for Health Workers. 2nd Edition Nigeria 1992.

Newell, ML., Coovadia, H., Cortina Borja, M., Rollins, N., Gaillard, P., Dabis, F. (2004). Mortality of infected and uninfected infants born to HIV-infected mothers in Africa: a pooled analysis. Lancet. (2004) 364:1236-1243

Olaniyi TO, Sunday P (2005). Oral manifestations of HIV infection in 36 Nigerian children. J Clin Pediatr Dent 2005; 30(1): 89-92

Obileye MF. (2006) Oral Manifestations of HIV/AIDS and response to Management in HIV positive children attending two dedicated paediatric HIV Outpatient clinics in Lagos State (Dissertation) Lagos, Nigeria: National Postgraduate Medical College of Nigeria, 2006

Obileye, MO., Agbelusi, GA., Orenuga OO \& Temiye EO. (2009). Dental Caries Status of HIV infected Nigerian Children. Nig. Qtr. J. Hosp Med. 2009; 19 (4):

Oleske J, Minnefor A, Cooper R Jr et al., (1983) Immune deficiency syndrome in children. J Am Med Assoc 1983; 249: 2345-49. 
Olumide YM (2002) A Self Instructional Textbook of Acquired Immune Deficiency Syndrome HIV/AIDS for Medical Students, Resident Doctors and Medical Practitioners. 1st edition Nigeria Longman, 2002

Onunu AN, Obuekwe N (2002) HIV Related Oral Diseases in Benin City, Nigeria. West Afr J Med 2002; 21(Jan/Mar): 9-11

Orne-Glieman Becquet R, Ekouevi DK, Leroy V, Perez F, Dabis F. (2008) Children and HIV/AIDS: From research to policy and action in resource-limited settings. AIDS. 2008; 23: 22 (7):797-805

Petersen PE. (2003). The World Oral Health Report 2003: continuous improvement of oral health in the 21st Century - the approach of the WHO Global Oral Health Programme. Community Dent Oral Epidemiol 2003; 31(Suppl. 1): 3-24

Petersen PE. (2004). Strengthening the prevention of HIV/AIDS-related oral disease: a global approach. Community Dent Oral Epidemiol 2004; 32: 399-401

Phelan JA, Jimenez V, Tompkins DC. (1997) Tuberculosis. Dent Clin North Am 1997; 40: 327 341.

Pinto A, De Rossi SS. (2004) Salivary Gland Disease in pediatric HIV Patients: An Update. J Dent Child 2004; 71(1): 33-37

Ramesh V. (1997) Tuberculoma of the Tongue Presenting as Macroglossia. Cutis 1997; 60: $201-202$.

Ramos -Gomez FJ, Hilton JF, Canchola AJ, Greenspan D, Greenspan JS \& Maldonado YA (1996). Risk factors for HIV-related Orofacial soft tissue manifestations in children. Pediatr Dent. 1996; 18(2): 121-6

Ramos-Gomez FJ, Greenspan D, Greenspan JS. Orofacial manifestations and management of HIV-infected children. In: Oral and Maxillofacial Surgery in Children and Adolescents. Kaban. LB. Ed. Philadelphia, WB Saunders Co. Pp 37-47

Ramos-Gomez FJ (1997) Oral aspects of HIV infections in children. Oral Diseases 1997; 3 (Suppl 1): S31-S35

Ramos-Gomez FJ, Flaitz C, Catapano P, Murray P, Milnes AR, Dorenbaum A \& Collaborative Workgroup on Oral manifestations of Paediatric HIV infection, Oral Aids Centre, University of California, San Francisco. (1999). Classification, Diagnostic Criteria, and Treatment Recommendations for Orofacial Manifestations in HIV-infected Pediatric Patients. J. Clin Pediatr Dent 1999; 23: 85 - 96.

Ramos-Gomez FJ, Petru A, Hilton JF, Canchola AJ, Wara D, Greenspan JS. (2000). Oral Manifestations and Dental Status in Paediatric HIV Infection. Int J Paediatr Dent 2000; 10: 3 - 11

Ranganathan K, Hemalatha R (2006). Oral lesions in HIV infection in developing countries: an overview. Adv Dent. Res. 2006; 19: 63-8

Rosemberg, ZD. Faucias, L (1994) Immunopathology and Pathogenesis of HIV Infection in pediatric AIDS. In: The Challenge of HIV Infection in Infants, children and adolescents (2nd Ed.), Pizzo AP, Wilfort CM, eds. pp. (115-127), Williams \& Wilkin, Baltimore.

Sauer G, Bredekamp A, Arendorf TM (1995) Proceedings of the 29th Scientific Congress of the International Association of Dental Research. Cape Town 1995: Abstract No. 85.

Schimdt-Westhausen A, Grunewald T, Reichart PA, Pohle HD. (1997) Oral Manifestations in 70 German HIV Infected Women 1997; 3 (Suppl 1):S28-S30

Scully C (1997) The HIV global pandemic: the development and emerging implications. Oral Diseases 1997; 3 (Suppl 1): 51-6. 1 
Soares, LF., de Araújo Castro, GFB, de Souza IPR \& Pinheiro M. (2004). Pediatric HIVrelated oral manifestations - a five-year retrospective study. Braz. Oral Res, 2004; 18(1):

Sowole CA, Orenuga OO, Chikte SA (2009). Access to oral health care and treatment needs of HIV positive paediatric patients Brazilian Oral Research and Integrated Pediatric Clinic. 2009 9(2): 141-146, maio/ago

Sullivan (2003). Prevention of Mother - to- Child Transmission of HIV - What Next? J AIDS 2003; 34: S67-72.

Swendeman D, Ingram BL, Rotheram-Borus MJ. (2009) Common elements in selfmanagement of HIV and other chronic illnesses: an integrative framework. AIDS Care. 2009; 21(10):1321-34.

Tofsky N, Nelson EM, Lopez RN, Catalanotto FA, Fine DH, Katz RV. Dental Caries in HIVInfected Children versus Household Peers: Two-Year Findings. Pediatr Dent 2000; 22: 207

Ukpebor M, Braimoh OB. (2007). HIV/AIDS; Oral Complications and Challenges, The Nigerian Experience. Benin Journal of Postgraduate Medicine 2007; 9(1):44-54

UNAIDS Joint United Nations Programme on HIV/AIDS (UNAIDS). Report on the Global AIDS Epidemic (2002). Geneva: UNAIDS, 2002

UNAIDS Joint United Nations Programme on HIV/AIDS (UNAIDS). Report on the Global AIDS Epidemic (2004). Geneva: UNAIDS, 2004.

UNAIDS/WHO (2005) Report on the Global AIDS Epidemic 2005. Geneva

UNAIDS. AIDS (2006). Epidemic Update - Special report on HIV/AIDS - December 2006. Geneva: UNAIDS; 2006.

UNAIDS (2009) Report on the Global AIDS Epidemic Update 2009. Geneva

Velegraki A, Nicolatou O, Theodoridou A, et al. Paediatric AIDS - Related Linear Gingival Erythema: A Form Erythematous of Candidiasis? J Oral Pathol Med 1999; 28: 178 182.

William DM (1993). In: EC - Clearing House on Oral Problems Related to HIV Infection of the Immunodeficiency Virus: Classification and Diagnostic Criteria for Oral Lesions in HIV Infection. J Oral Pathol Med 1993; 22: 289 - 291.

World Health Organization. (2003) Global Health-Sector Strategy for HIV/AIDS 2003-2007. Geneva: WHO, 2003.

World Health Organization (2003) The World Health Report, Shaping the Future. Geneva: WHO, 2003

Working Group on Mother To Child Transmission of HIV. Rates of mother- to- child transmission of HIV-1 in Africa, America and Europe: Results from 13 perinatal studies. Journal of Acquired Immune Deficiency Syndrome and Human Retrovirology 1995; 8: 506-510

Wright AA. (2003) A Study of Oral Manifestations of HIV/AIDS and Response to Management at the General Hospital Lagos, Nigeria (Dissertation) Lagos, Nigeria: National Postgraduate Medical College of Nigeria, 2003;48

Yengopal V, Bhayat A, Coogan M. (2011). Pediatric Oral HIV Research in the Developing World. Adv Dent Res. 2011; 23(1): 61-6.

Zijenah LS, Katzenstein DA (2002). Immunopathogenesis of AIDS In: AIDS in Africa., Essex M, Mboup S, Phyllis J, Richard K, Marlick G, Tiou SD. Pp 35,Khuser Academic /Plenum Publishers, New York. 


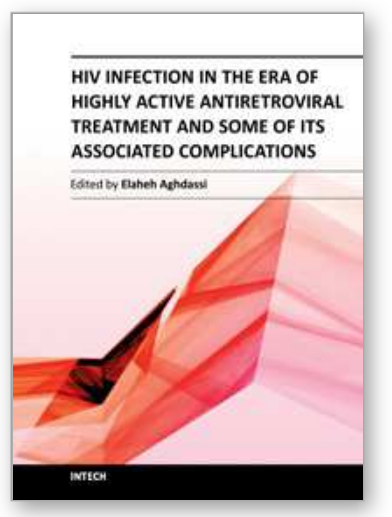

\section{HIV Infection in the Era of Highly Active Antiretroviral Treatment and Some of Its Associated Complications}

Edited by Dr. Elaheh Aghdassi

ISBN 978-953-307-701-7

Hard cover, 212 pages

Publisher InTech

Published online 14, November, 2011

Published in print edition November, 2011

Human immunodeficiency virus (HIV) infection is a complex illness affecting the immune system. Acquired immunodeficiency syndrome (AIDS) is an advanced form of HIV infection in which the patient has developed opportunistic infections or certain types of cancer and/or the CD4+ T cell count has dropped below 200/ $\mathrm{LL}$. More than 40 million persons around the world are infected with HIV, with approximately 14,000 new infections every day. The disease causes 3 million deaths worldwide each year, $95 \%$ of them in developing countries. Optimal management of human immunodeficiency virus requires strict adherence to highly active antiretroviral treatment (HAART) regimens, but the complexity of these regimens (e.g., pill burden, food requirements, drug interactions, and severe adverse effects) limits effective treatment. However, more patients with HIV are surviving longer today because of these drugs. This allows further study of commonly associated adverse effects. These may affect all body systems and range from serious toxicities to uncomfortable but manageable events. This book reviews some of HAART-related metabolic and neurological complications.

\section{How to reference}

In order to correctly reference this scholarly work, feel free to copy and paste the following:

Omolola Orenuga, Mutiat Obileye, Christiana Sowole and Gbemisola Agbelusi (2011). Oral Manifestations of Paediatric HIV Infection, HIV Infection in the Era of Highly Active Antiretroviral Treatment and Some of Its Associated Complications, Dr. Elaheh Aghdassi (Ed.), ISBN: 978-953-307-701-7, InTech, Available from: http://www.intechopen.com/books/hiv-infection-in-the-era-of-highly-active-antiretroviral-treatment-and-someof-its-associated-complications/oral-manifestations-of-paediatric-hiv-infection

\section{INTECH}

open science | open minds

\section{InTech Europe}

University Campus STeP Ri

Slavka Krautzeka 83/A

51000 Rijeka, Croatia

Phone: +385 (51) 770447

Fax: +385 (51) 686166

www.intechopen.com

\section{InTech China}

Unit 405, Office Block, Hotel Equatorial Shanghai

No.65, Yan An Road (West), Shanghai, 200040, China 中国上海市延安西路65号上海国际贵都大饭店办公楼 405 单元

Phone: +86-21-62489820

Fax: $+86-21-62489821$ 
(C) 2011 The Author(s). Licensee IntechOpen. This is an open access article distributed under the terms of the Creative Commons Attribution 3.0 License, which permits unrestricted use, distribution, and reproduction in any medium, provided the original work is properly cited. 